\title{
Julio Ruiz Berrio: Memoria do traballo compartido en dous tempos
}

Se ben dende había xa algúns anos viñámolo vendo un tanto desmellorado, non por iso deixou de sorprendernos e conmocionarnos a mensaxe que Antonio Viñao nos remitiu na primeira hora da tarde do pasado 9 de outubro, a través da canle institucional máis rápida e uída da que dispoñemos, informándonos de que Julio Ruiz Berrio acababa de falecer. A triste nova do pasamento dunha persoa achegada ou amiga actúa sempre como eficaz resorte activador de recordos dos momentos e experiencias con ela compartidos. $E$ máis aínda cando, como é o caso, aquel que se nos vai permanece no enxoval das nosas vidas como un referente de humanidade e un mestre na órbita intelectual. Dalgúns deses recordos sobrevidos de súpeto no intre do desacougo e o abatemento quero ocuparme de maneira sucinta neste texto, na mesma medida en que, coa distancia dos días, a memoria me asista.

Ao igual que tantos outros da miña promoción, pertencentes ás diversas universidades españolas, coñecín a Julio persoalmente co gallo do I Coloquio de Historia da Educación, celebrado en Alcalá de Henares a comezos de outubro de 1982, se ben na primavera dese ano xa o vira de lonxe en Compostela na defensa da tese de doutoramento de Herminio Barreiro que el dirixira. Como se dunha cerimonia de iniciación se tratase -que algo diso tivo, conforme acreditou o decorrer dos anos- alá fomos en caravana automobilística un numeroso grupo de galegos -cadaquén con cadansúa comunicación- que por avultado e ben avido causou entre estrañeza, admiración e receo entre os demais congresistas. Eu tíñalle oído falar de Ruiz Berrio tanto a José M. Touriñán como a Herminio Barreiro. O primeiro suxerírame o seu nome como posible director da miña futura tese, na que por entón daba os primeiros pasos baixo a cobertura dunha bolsa de formación de persoal investigador para desenvolver un proxecto daquela formalmente supervisado polo propio profesor Touriñán. O segundo, coa experiencia próxima acumulada da xestación da súa pescuda, compartía no tocante ao meu doutoramento o parecer daquel. Touriñán comentoulle a idea a Julio e este aceptou de moi bo grado a proposta. Con todo, naquela primeira edición dos coloquios, o encontro co profesor Ruiz Berrio debeu ser breve e fugaz. 0 asunto nin urxía nin era máis que un bocexo de incipiente factura. E había moitas outras cousas que arranxar naquela ocasión de maior calado e superior transcendencia. Máis detidas foron as conversas os anos seguintes no marco tamén das sucesivas convocatorias dos coloquios en Valencia (1983) e Barcelona (1984), así como no Congreso de Pedagoxía en Santiago de Compostela (1984). A partir deste último ano fíxose cargo de maneira efectiva da dirección do meu traballo. Lembro que ás entrevistas que con el mantiñamos os doutorandos procedentes de distintos puntos da península con motivo das citas congresuais, prefería e acostumaba convocarnos cediño, a primeira 
hora da mañá, antes de iniciar as actividades ordinarias e mesmo de almorzar; isto é, en sesión de «maitines». E, polo regular, a entrevista discorría segundo o modelo peripatético polos parques, xardíns e rúas da contorna, sempre que non mediasen papeis. É dicir, camiñabamos xuntos polos arredores do recinto congresual ou de aloxamento mentres comentabamos os avances, dúbidas e dificultades das nosas investigacións. Logo xa, a medida que o traballo ía tomando corpo e dispoñiamos de textos escritos, optaba por realizar a revisión sentados, para maior comodidade dos interlocutores, pero polo regular fóra dos despachos, procurando fomentar un clima de distensión que en situacións de rendemento de contas moito se agradecía.

Venme á memoria unha anécdota ocorrida, debeu ser, nos primeiros meses de 1986. Fomos visitalo a Oviedo en misión de traballo Xosé Manuel Cid e máis eu. Fixemos a viaxe en coche. El chegaba de Madrid en avión como adoitaba case todas as semanas. Recollémolo a media tarde no aeroporto asturiano de Avilés para logo dirixirnos á cidade do Carbayón. Previsor e condescendente como sempre era, xa se encargara de reservarnos os cuartos para pasar a noite na pousada onde el se hospedaba. E non satisfeito con iso, convidounos a cear, degustando xuntos pratos típicos da terra, seguindo as súas indicacións, adubados con animada parola que, como bo conversador, alimentaba. Aquela forma de proceder resultoume a un tempo desconcertante e reveladora da calidade humana do noso director. Ao día seguinte tocou traballar, aproveitando os intervalos de descanso entre clase e clase na Facultade. Pero a lección máis importante para min xa nola tiña ensinado. Boa proba diso é que fica gravada alí onde acougan os recordos indelebles.

No longo itinerario de elaboración da tese -no que a min atinxe, sen hipérbole de ningún tipo- sempre tivo palabras de comprensión e alento. Por veces un chisco retranqueiras e incisivas, sen chegar a ser ferintes, como querendo apelar ao amor propio, á autoestima, pero facendo valer os talentos e as capacidades dun mesmo para afrontar os retos. Esa confianza na propia competencia persoal que constantemente transmitía, erixiuse no principal acicate para vencer 0 abatemento e superar o desánimo que con máis frecuencia da desexable asomaba no horizonte de moitos días, sobre todo cando aínda o labor de indagación non se vía materializado na primeira síntese narrativa.

Despois xa de redactados os borradores iniciais todo resultou algo máis livián e levadeiro. E se a distancia seguía a constituír un atranco para a comunicación persoal directa, tiña como contrapartida favorable o feito de afianzar o traballo autónomo. Precisamente foi esta unha das vertentes da investigación na que o profesor Ruiz Berrio nunca interferiu, sen que isto comportase situacións de desamparo ou desatención cara ao investigador pola súa parte. Antes ao contrario, un sabía que sempre podía recorrer a el na procura do asesoramento requirido. Abondaba cunha chamada telefónica, á facultade ou á casa, a calquera hora do día, coa seguridade de que un ía recibir a orientación precisa ou a verba amable. Esas que cómpren en ocasións de incerteza cando non se logran dilucidar con diafanidade os problemas que se afrontan ou non se conseguen perfilar con tino as fronteiras da investigación emprendida. Así me ocorreu a min cando despois de levar máis de 1200 páxinas escritas sobre a temática elixida para a tese e tendo unha parte pendente de construción, segundo o esquema inicial, me recomendou con sabedoría e pragmatismo 
poñer cabo a aquel informe que na súa versión final aínda chegaría a sumar outras 400 . Comprendín e aceptei a recomendación que me deu. E con ela sentinme moi aliviado, se ben é certo que unha miga contrariado ao non poder completar naquela ocasión 0 proxecto de partida, adiando o tratamento dunha parte monográfica non menor que, no suposto de acometela de acordo co plan previsto, acabaría sendo unha desmesura e, se cadra tamén, un farallón insuperable na miña traxectoria profesional. Velaí exemplificada nunha das súas facetas a función do director que acompaña e asiste no proceso de toma de decisións, imprimíndolle a perspectiva realista, da cal -por veces-, o investigador en formación carece.

No acto de defensa da tese (1990), Julio volvería amosar de novo a súa xenerosidade cando ao intervir na quenda que lle correspondía quixo dedicarlle as primeiras palabras a José Manuel Touriñán como testemuño de recoñecemento pola oportunidade que lle brindara de dirixir aquel traballo, co que se sentía moi compracido e até intelectualmente identificado. Convén engadir en relación con isto último que en simultaneidade coa miña dirixiu outras dúas teses centradas total ou parcialmente na mesma materia: a de Miguel Zapater sobre as achegas educativas dos emigrantes na Rioja (1989) e a de Ángel Mato en torno á escolarización e o analfabetismo en Asturias (1990), ambas as dúas felizmente publicadas ao pouco tempo de seren defendidas. E el mesmo escribiu uns anos máis tarde unha comunicación acerca do tema, dende unha perspectiva territorial e cronolóxica diferente, que presentou no Coloquio de Historia da Educación celebrado en Santa Cruz de Tenerife (1994).

Rematada a tese, en varios momentos me indicou que tiña que facer todo o posible para xestionar decontado a súa edición. E, por sorte, apenas seis meses despois puiden confirmarlle que, efectivamente, a Xunta de Galicia aprobara a publicación da obra, garantíndome que o texto do informe vería a luz íntegro, e que ademais tería oportunidade de enriquecelo con abundantes elementos gráficos que non figuraban na versión orixinal, conferíndolle así un valor e un atractivo dignos de mención que eran moito de agradecer pola miña parte. Díxenlle tamén que, por razóns de política editorial, o libro levaría só unha presentación institucional, non sendo factible incorporarlle un preámbulo seu, como era a miña intención e vontade, e en ningún caso tampouco se amentaría a procedencia académica daquel estudo nin, por suposto, ao director do mesmo. Antollábase inverosímil, pero pareceu entendelo e admitir as condicións sen reserva, restándolles importancia e aseverando que o fundamental era que a investigación se publicase completa; todo o demais tiña un carácter accesorio. Sentinme compracido de que así pensase porque levaba dándolle moitas voltas ao asunto antes de comentalo con el e pesaba sobre min un certo sentimento de culpabilidade ou de ingratitude que non sabía como emendar. No entanto, transcorridos algúns anos (1994) comprobei con mágoa que se sentira un tanto agraviado ao ver silenciado o seu nome na obra impresa, omisión da cal fixo partícipe de puño e letra a toda a comunidade científica, salientando porén o elevado concepto que lle merecía 0 traballo e as fortalezas que posuía. Captei a mensaxe e lamentei non estar en condicións de corresponder nalgunha medida. Dende entón nunca máis volvemos ocuparnos daquel desagradable episodio, para nós os dous, polo que nos vimos absolutamente rebordados. 


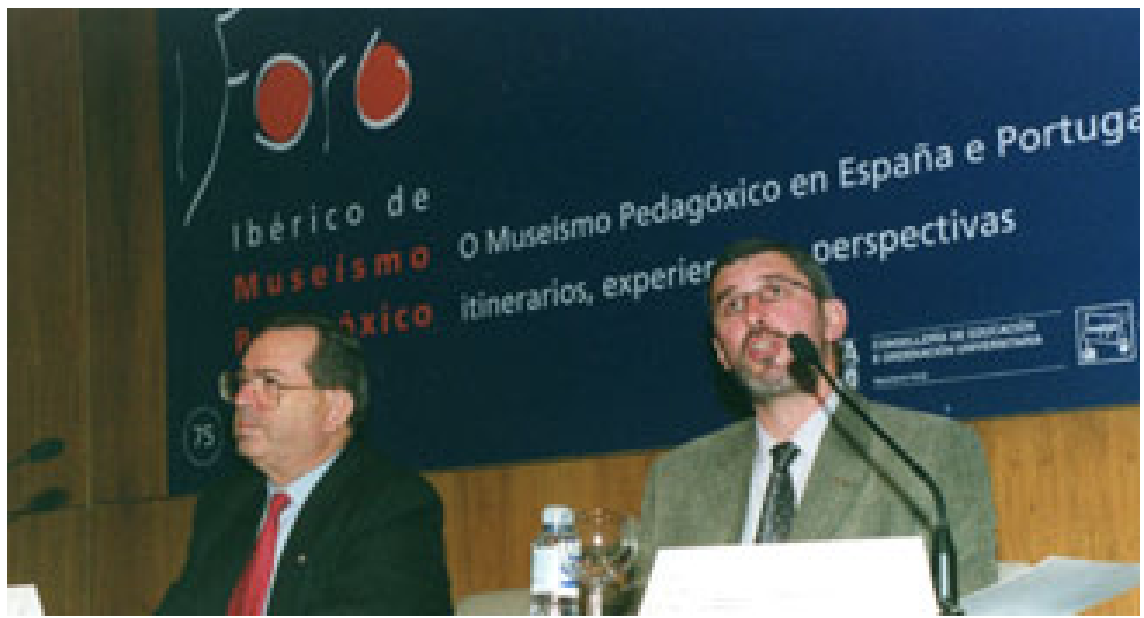

I Foro Ibérico de Museísmo Pedagóxico. Santiago de Compostela, 8-11-2001. Julio Ruiz Berrio e Vicente Peña Saavedra.

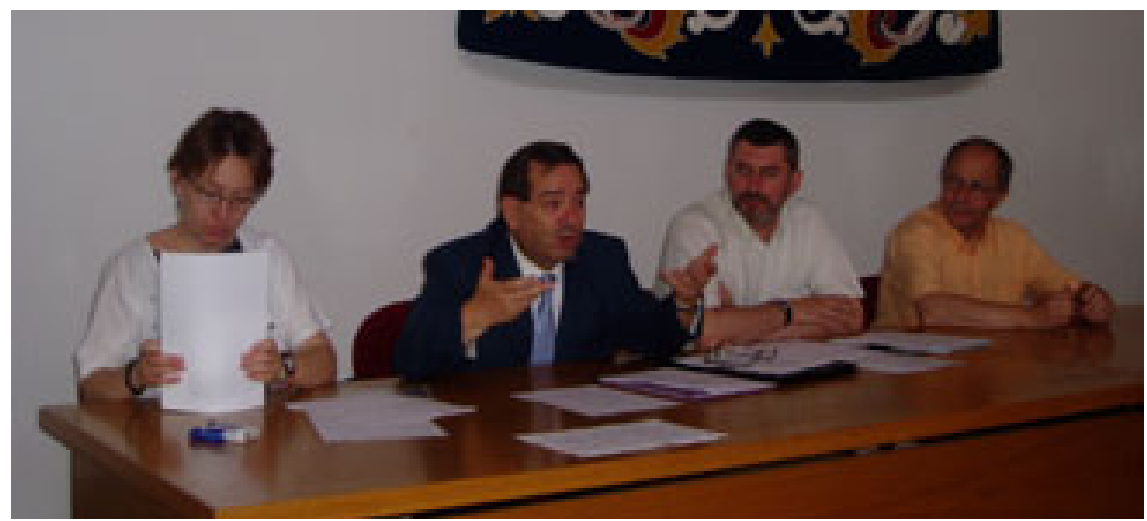

Asemblea constituínte da SEPHE. Burgos, 18-6-2003. De esquerda á dereita, Francesca Comas Rubí, Julio Ruiz Berrio, Vicente Peña Saavedra e Josep González-Agápito.

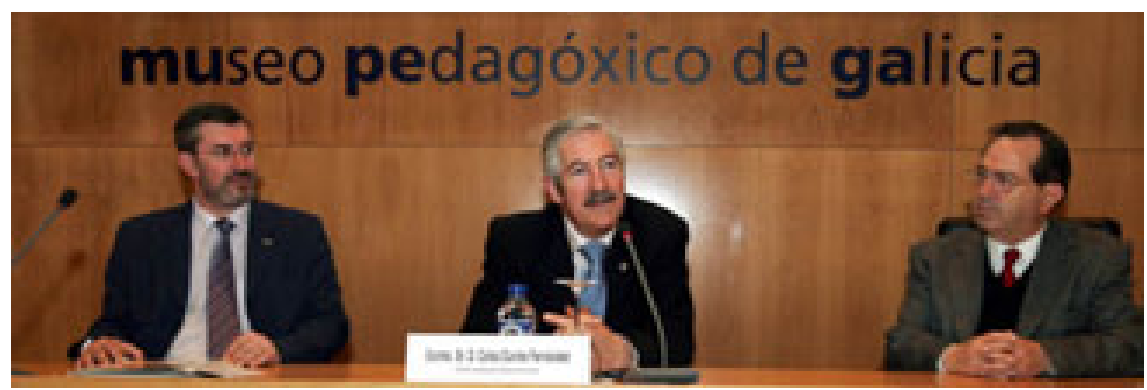

Acto de clausura das I Xornadas Científicas da SEPHE. Santiago de Compostela, 13-5-2005. De esquerda a dereita, Vicente Peña Saavedra, Celso Currás Fernández e Julio Ruiz Berrio. 


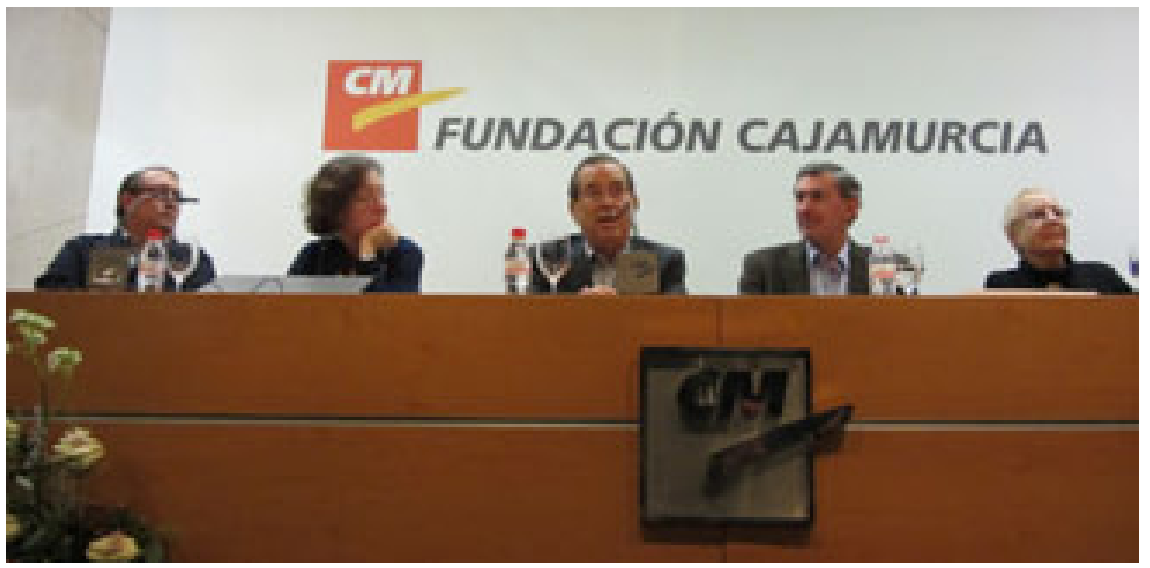

Última Asemblea Xeral da SEPHE presidida por Julio Ruiz Berrio. Murcia, 22-11-2012. Acompañan ao presidente, á esquerda, José Mํa Hernández Díaz e Francesca Comas Rubí, e á dereita, Vicente Peña Saavedra e Mํa Nieves Gomez García, integrantes da Xunta Directiva.

Polas mesmas datas presidiu o tribunal da miña oposición a profesor titular, actuando con elegancia, ecuanimidade e rigor.

Durante a segunda metade da década dos 90 continuamos coincidindo nalgún Coloquio de Historia da Educación e noutras actividades académicas. Pero até 1998 mantivémonos un tanto afastados, cada quen ao seu, sen saber moito 0 un do outro. Neste último ano convidoume a participar cun relatorio nas xornadas conmemorativas do centenario do Noventaeoito que co-organizou na Universidade de Zaragoza. O encontro foi fuxidío, emporiso serviu para restablecer de preto unha relación que se arrefriara nos últimos anos. Nesa fronteira intersecular sitúase o tránsito dun a outro tempo aos que fago mención no título desta achega.

Dende comezos de 1999 vin traballando no proxecto MUPEGA, que cristalizou formalmente como centro museístico a finais de 2000. E un ano despois (novembro de 2001) organizamos dende el o I Foro Ibérico de Museísmo Pedagóxico. No Foro interveu como primeiro conferenciante da área educativa o profesor Ruiz Berrio, quen se ocupou do museísmo pedagóxico no mundo. $O$ texto da súa conferencia e o posterior coloquio que suscitou quedaron recollidos no libro de actas que demos ao prelo máis adiante (2003). № seo desa convocatoria foral aprobamos co beneplácito de todos os asistentes as «Bases para unha Rede lbérica de Museísmo Pedagóxico", nas cales se estipulaba, entre outras cousas que o lector interesado poderá consultar na publicación, «crear, cando as circunstancias o permitan, unha Rede Ibérica de Museos Pedagóxicos [...] que contribúa a propiciar e afianza-la comunicación, a transmisión de saberes e a realización de traballos conxuntos entre cantos están dedicados á museoloxía e á investigación na área educativa en España e Portugal». Pero tan interesantes como os acordos e as conclusións expresas que se derivaron do Foro resultaron seren, con visión prospectiva, as aprendizaxes prácticas que do mesmo dimanaron como secuela do encontro e intercambio de pareceres cos colegas do país veciño. 
A máis relevante, ao meu criterio, a da necesidade de proceder de forma inmediata a integrar nunha estrutura organizativa estable as distintas experiencias museográficas que no ámbito da educación viñan abrollando en España dende a segunda metade da década dos 80 e que non conseguían atinxir até entón a visibilidade e proxección desexables. Como consecuencia desta constatación ao ano seguinte (2002) celebrouse en Palma de Mallorca a I Trobada de Museus i Historiadors de l'Educació. Nela acordouse, cunha certa ambigüidade nominal e configurativa, iniciar as xestións conducentes á constitución dunha entidade para a que, provisoriamente, se escolleu o nome de "Sociedad de Amigos de Museos de Educación» (SAME), designándose unha comisión permanente encargada de levar a termo as accións propedéuticas conducentes á súa fundación. Francesca Comas suxeriu ademais nesa xuntanza que se tomara e publicara como texto teórico da articulación proposta a conferencia pronunciada por Ruiz Berrio o primeiro día, que levaba por título: «Metamorfosis de los Museos de Educación: nuevos enfoques y nuevas perspectivas", e que na súa segunda versión, desta volta en lingua catalana, se difundiu a través das páxinas da revista Educació i História $(6,2003:$ 172-185). Un ano despois, no contexto do XII Coloquio de Historia de la Educación, celebrado en Burgos, quedou constituída a que acabaría sendo "Sociedad Española para el Estudio del Patrimonio Histórico-Educativo». Por certo, nese Coloquio déuselle cabida auroral a unha sección dedicada á "Museología de la educación», que tería continuidade nalgunhas das edicións posteriores. Na mesma asemblea fundacional foi elixido Julio Ruiz Berrio presidente da primeira Xunta Directiva. A entidade aínda demoraría un ano en ser inscrita no rexistro nacional de asociacións, tarefa que, canda outras de tipo burocrático, lle ocasionou moitos desvelos ao seu máximo representante. Por xentileza súa e co apoio dos socios fundadores tiven a honra de acompañalo como vicepresidente da asociación durante os dous mandatos en que estivo á fronte dela (2003-2012). Nesta singradura que abrangue dende o I Foro de Compostela (2001) até o III Foro de Murcia (2012) participamos xuntos nunha morea de actividades congresuais relacionadas co patrimonio históricoeducativo e a súa musealización, que tiveron lugar en enclaves como: Porto, Santarém, Polanco, Salamanca, Allariz, Buenos Aires, Vic, Berlanga de Duero, Huesca, Donostia..., amais dos xa citados. Todas elas deixaron unha particular pegada formativa e emocional en min e estou seguro de que nel tamén, como igualmente o farían nos distintos colegas que as programaron ou a elas concorreron. Resultaría imposible glosalas todas aquí. $E$ de verme no brete de escoller unha sería, por razóns obvias, a correspondente ás I Xornadas Científicas da SEPHE que nos coubo a honra de organizar ao equipo humano do MUPEGA, por mandato da corporación patrocinadora, na primavera de 2005. Os actos discorreron nun ambiente moi cálido no que primou 0 debate aberto arredor dos centros museográficos xa en funcionamento, as experiencias museísticas en fase de xestación e outras iniciativas de recuperación e valorización do patrimonio educativo e da infancia. Aprobouse un compendio de oito conclusións nas que, ante todo, se patentizaba o optimismo dos participantes en canto ao panorama dos museos de educación en España, ao tempo que se re ectía a vontade de darlles continuidade ás Xornadas en futuras edicións e o compromiso de fortalecer a SEPHE con fórmulas e recursos moi diversos. Do labor desenvolvido quedou constancia nun documento multimedia, no cal se recolle o testemuño audiovisual da intervención do profesor Ruiz Berrio no primeiro acto congresual en que oficiou como presidente da SEPHE. No transcurso das Xornadas plasmou, así mesmo, o seu parecer sobre o MUPEGA no 
Libro de sinaturas do establecemento. Nel escribiu: «jFelicitaciones por la consecución de este Centro que se ha convertido en la Catedral de los Museos de Educación de España y Europa!» Apenas un mes despois, un xornal de ámbito nacional dedicoulle ao MUPEGA un suplemento monográfico, para o cal os xornalistas estiveron recompilando información directa no museo durante varios días. Cando me entrevistaron a min, mencioneilles a valoración que del fixera en datas recentes o presidente da SEPHE quen, á sazón, era tamén director do "Museo-Laboratorio de Historia de la Educación, Manuel Bartolomé Cossío», da Universidad Complutense de Madrid. Sen máis cultura pedagóxica que a implícita na devandita información e cun descoñecemento absoluto do persoeiro que daba nome ao museo madrileño por parte da redactora da reportaxe-entrevista, esta apareceu rotulada cun inopinado e anacrónico titular, para máis infortunio entre comiñas, que proclamaba: «Manuel B. Cossío cualificouno como a catedral dos museos da educación». Mi madriña! Nunca me atrevín a comentarlle a Julio semellante disparate, revelador dun pensamento de marcado signo ahistórico ou de palmar fasquía presentista. Por máis que, teño para min a día de hoxe, non deixaría de resultarlle pavero alén de penoso. Como cando, anos atrás, lle adxudicaron unha obra súa a Tuñón de Lara na bibliografía dun artigo meu publicado nunha revista especializada. Cando llo contei, respondeu con retrónica: «mientras me confundan con él, no habrá problema; sabré disculpárselo».

Axiña chegaría o que ben podería catalogar como o meu particular bienio horribilis (2006-2007). Nel, logo de cesarme os progresistas con argumentos un tanto peregrinos como coordinador científico do MUPEGA, tentaron aldraxar á SEPHE, de maneira ruda e torpe, pola miña representación directiva nela, afastándoa do patrocinio científico do I Encontro Iberoamericano de Museos Pedagóxicos e Museólogos da Educación (2008). Dende o primeiro momento, Julio como presidente alzou a voz e esgrimiu a pluma en defensa da nosa asociación, pedindo responsabilidades ás máis altas instancias, sen que ninguén soubera darlle unha acaída razón. De seguido actuou en consecuencia. Non todos o fixeron, preferindo algúns virarse de costas ou mirar para outro lado. Tampouco son eu quen, evidentemente, para recriminárllelo.

Ás portas da xubilación como docente e investigador universitario (2010) aínda nos regalou unha penúltima ensinanza, ao presentar a dimisión irrevogable da presidencia da SEPHE, por entender que «un Presidente de una Sociedad debe ser un profesional en activo». Os demais membros da directiva non lle aceptamos a renuncia e pedímoslle que continuase dous anos máis, até que se celebrasen novas eleccións. Así o fixo con extraordinaria xenerosidade, por máis que a aquela altura a súa saúde xa se tiña resentido dabondo. Concluído o noso mandato, tralas oportunas eleccións en novembro de 2012, todos cantos tivemos o privilexio de ostentar a representación executiva da SEPHE dende a etapa fundacional, cedemos a testemuña ao equipo que rexe arestora os destinos da nosa asociación.

O legado humano e intelectual de Julio Ruiz Berrio, do que tanto aprendemos no pasado, con seguranza, continuará a iluminarnos no porvir. Gratitude e beizón.

Vicente PEÑA SAAVEDRA

Universidade de Santiago de Compostela 